\title{
CORRIGENDUM
}

\section{Folate intakes and folate biomarker profiles of pregnant Japanese women in the first trimester}

\author{
N Mito, H Takimoto, K Umegaki, A Ishiwaki, K Kusama, H Fukuoka, S Ohta, S Abe, M Yamawaki, \\ $\mathrm{H}$ Ishida and $\mathrm{N}$ Yoshiike
}

European Journal of Clinical Nutrition (2007) 61, 566. doi:10.1038/sj.ejcn.1602646

Correction to: European Journal of Clinical Nutrition (2007) 61, 83-90. doi:10.1038/sj.ejcn.1602497

Since the publication of this issue, the authors have identified some errors in the following pages. In page 86 , under the heading Dietary intake, the last sentence should read more than $70 \%$ of subjects had a folate intake below $200 \mu \mathrm{g} / 1000 \mathrm{kcal} /$ day.

In page 87, Figure 2 and its caption should read as follows. In this same page, second paragraph should read the

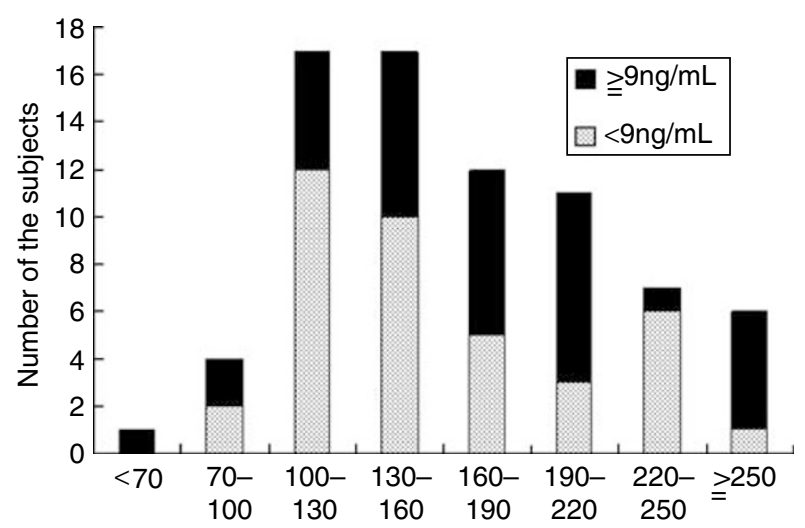

Dietary folate intake $(\mu \mathrm{g} / 1000 \mathrm{kcal} / \mathrm{day})$

Figure 2 Distribution of folate intake per $1000 \mathrm{kcal}$ in groups defined by serum folate concentration. Gray bar: low folate group $(<9 \mathrm{ng} / \mathrm{ml})$, black bar: high folate group $(\geqslant 9 \mathrm{ng} / \mathrm{ml})$. recommended dietary allowance (RDA) of folate in early pregnancy for prevention of NTD is $440 \mu \mathrm{g} /$ day in the Dietary Reference Intakes for Japanese, 2005 (Ministry of Health, Labour, and Welfare, Japan, 2005). Mean folate intake/day in all subjects was $289 \mu \mathrm{g} /$ day in the present study. Only $7 \%$ of subjects had a folate intake above $440 \mu \mathrm{g} /$ day, and folate intake was below the RDA in $93 \%$ of subjects'.

The authors apologize for any inconvenience this may have caused. 